\title{
Interactive comment on "Cloud-venting induced downward mixing of the Central African biomass burning plume during the West Africa summer monsoon" by Alima Dajuma et al.
}

\section{Anonymous Referee \#1}

Received and published: 19 August 2019

\section{General Comments}

The manuscript has an important goal-investigate the hypothesis that "cloud venting plays a considerable role in the downward mixing of biomass burning aerosol" (line 74). Achieving that goal would be of great interest to everyone in the field because so little is known about it. Unfortunately, the manuscript does a very poor job of investigating the topic. Many figures are shown and discussed, but none directly address the cloud venting issue. There is no systematic laying out of evidence to support the hypothesis. Nonetheless, the authors make unsupported speculations about how cloud venting could be a factor in what is being shown. Sad to say, but after finishing the manuscript 
I felt that I had learned nothing about cloud venting.

Major Issues

1. The Introduction contains no information about previous studies of downward transport by convection (your topic). If any exist, they should be described. Your work should pick up where the previous studies left off.

Interactive

comment

2. Line 150-It is unclear how the case study of 02-03 July was conducted. Did you use the COSMO simulated meteorology, but instead of the MOZART chemistry, you specified the simplified $\mathrm{CO}$ profile? The details of the case study methodology must be better described. ${ }^{\star \star \star}$ This description will be critical to the success of the manuscript. Readers must know what you did before they can assess what the results show.

3. State the reason why you chose 02-03 July for the case study. Was it typical of all July days or was it picked for a particular reason?

4. Line 221-Observed vs. simulated CO in Fig. 4. There are some major differences in the two fields. You say that features are "reasonably captured". That is a very generous assessment that I believe should be 'toned down'.

5. Line 240-1-As mentioned in the General Comments, I maintain that you do not 'especially focus on the role of convective clouds'. That is my fundamental problem with the manuscript; the results seldom address the hypothesis.

6. Line 275-"conspicuous north-south orientation" of cells. I don't see this.

7. Section 4.2-The oceanic area should be the focus of this section. While it is good to have simulated/observed agreement over land, it is especially important that this area be well simulated because you later will show cross sections and area averages in this region. So. . . a change in focus is needed in this section.

8. Figure 6-Panel c) contains simulated precipitation rate at 1800 UTC while panels a) and $b$ ) are for 1200 UTC. Why the time change? The text says nothing about convective

Printer-friendly version

Discussion paper 
evolution between the two times. Also, does panel b) comprise the same area as the other panels? There are no lat/long indications on $b$ ).

9. Figure 7 does not cover the same domain as Figs. 5 or 6 . This makes a comparison of features very difficult. I suggest you place a dashed line at $4 \mathrm{~N}$ as done in earlier figures. Please outline the area in Fig. 7 that corresponds to the area in Fig. 6 .

Also, Fig. 8 will show that the level of maximum $\mathrm{CO}$ is $\sim 2000 \mathrm{~m}$. That would seem a better choice for Fig. 7 than 2900 m. Or. ....you could add $2000 \mathrm{~m}$ as a third panel to Fig. 7.

10. Line 311-There is no justification for this transport statement.

11. Line 313-I do not see a CO feature at $2900 \mathrm{~m}$ that is "west and north of the main plume". Also, what is your rationale for stating that this could be due to downward mixing?

12. Line 331-How does Fig. 8 indicate that the biomass plume is advected in a westerly direction?

13. Line 341 and Fig. 8d (cloud liquid water)-How does this panel indicate positive and negative vertical motions?

14. Line 345-What do you mean by "less evidence of convective mixing"?

15. Line 361 , simulations initialized-Is this truly a new and different model run initialized on 2 July? I had assumed that you were using the meteorology for 2-3 July from the simulation begun on 25 June (the run you have been describing up to this point). However, now you have used the simple CO profile, not the MOZART-derived CO. I am confused. You must explain what you are doing. This is the same issue raised in question 2 above.

16. Figure 9-You show the layers below $1 \mathrm{~km}$, between $2-4 \mathrm{~km}$, and the sum "between the two". Why did you not include the layer between $1-2 \mathrm{~km}$ ? 
17. Line $399+$ and Fig. 10-I do not understand the purpose of relating SST to \% mass. How does this relate to cloud venting? You must explain the relevance of this figure to your hypothesis.

\section{Minor Issues}

1. Describing locations by city names should be avoided. Most readers will have insufficient geographic knowledge of these city locations. Either provide a map showing all cities that are mentioned or completely avoid the use of city names.

2. Line 146-What are the horizontal and vertical grid spacings of the ICON and MOZART data that are used for your ICs and BCs? State these in the text.

3. Line 151-Is your model configured with one-way or two-way interactions between D1 and D2? State this in the text.

4. Line 165-I assume that D1 and D2 are being run concurrently. However, line 165 ("over D1") gives me doubt. Please re-phrase to make this clear.

5. Figure 2 should be in color like the other figures.

6. Figure $3 \mathrm{~b}-$ The abrupt gradient in MODIS-derived cloud cover at $4.5 \mathrm{~N}$ is very suspicious looking. Could this be a data problem, or is it real?

7. Figure 7 caption-Do you mean that all the cooler regions west of $3 \mathrm{~W}$ over the water are cold pools related to convective cells? If only certain regions represent cold pools, those should be denoted by arrows. Also, it would strengthen your argument that these are convectively related cold pools by referring to Fig. $6 \mathrm{c}$ which shows that there was plenty of simulated rainfall in the area (at least $6 \mathrm{~h}$ later at 1800 UTC).

8. Line 347 (Fig. 8f)-The panel label for f) says 1 deg W, not 1 deg $E$.

9. Figure 9-Dates on the x-axis should be labeled.

Please also note the supplement to this comment: 
https://www.atmos-chem-phys-discuss.net/acp-2019-617/acp-2019-617-RC1supplement.pdf

ACPD

Interactive comment on Atmos. Chem. Phys. Discuss., https://doi.org/10.5194/acp-2019-617, 2019.

Interactive

comment 